\title{
Effect of vaginal progesterone in combination with cervical cerclage on improved gestational age and perinatal outcome in twin pregnancy: A prospective randomized study
}

\author{
Abdelaal N.*, Sanad Z., Shaheen A., Hamza H., Al Halaby A.
}

Department of Obstetrics and Gynecology, Menoufia University, Egypt

Received: 14 May 2017

Accepted: 10 June 2017

*Correspondence:

Dr. Abdelaal N.,

E-mail: nasserkamal411@gmail.com

Copyright: () the author(s), publisher and licensee Medip Academy. This is an open-access article distributed under the terms of the Creative Commons Attribution Non-Commercial License, which permits unrestricted non-commercial use, distribution, and reproduction in any medium, provided the original work is properly cited.

\begin{abstract}
Background: Prematurity is the second leading cause of death in the first month of life. Objective of present study was to evaluate the effectiveness of vaginal progesterone and cervical cerclage each alone and in combination in improving gestational age in twin pregnancy and its subsequent impact on perinatal outcome.

Methods: A sample size of seventy-five patients has been calculated out of those recruited from outpatient clinic at menoufia university hospital. All fulfilled eligibility criteria of having a twin pregnancy with a history of spontaneous preterm labour, or with a sonographic short cervical length $<25 \mathrm{~mm}$ in mid trimester. The participants were randomly assigned to three groups. Group $1(\mathrm{~N}-25)$ : received vaginal progesterone supplementation of $200 \mathrm{mg}$ from 20 weeks until 34 weeks of gestation. Group2 (N-25): were remedied with cervical cerclage of Mc Donald type at 14-16 weeks of gestation Group $3(\mathrm{~N}-25)$ : received both vaginal progesterone as well as cervical cerclage. The primary outcome measure was spontaneous delivery between 34-37 weeks of gestation. Secondary outcomes were delivery prior 34 weeks of gestation as well as some parameters of neonatal morbidity and mortality.

Results: There was a statistically significant higher gestational age in combination group when compared to progesterone group or cerclage group $(\mathrm{P}<0.001)$. Comparison between progesterone and cerclage groups did not reach statistical significance $(\mathrm{P}=-0.85)$. Both progesterone and cerclage groups demonstrated significantly lower birth weights, lower Apgar scores and a higher NICU admission rate than in combination group $(\mathrm{P}<0.001)$, while such significant difference did not exist between progesterone and cerclage groups.

Conclusions: Combination of vaginal progesterone and cervical cerclage can improve gestational age at delivery as well as some parameters of perinatal morbidity and mortality in twin pregnancy.
\end{abstract}

Keywords: Cerclage M, Preterm birth, Twin gestation, Vaginal progestrone

\section{INTRODUCTION}

Prematurity is the second leading cause of death in the first month of life. ${ }^{1}$ Several randomized studies have provided an evidence that progesterone supplementation can result in significant reduction of preterm birth and neonatal morbidity and mortality. ${ }^{2}$ Cervical cerclage has reduced the risk of preterm labour for selected population of singleton pregnancies,as those with history of preterm birth and a shortened cervix. ${ }^{3}$ About half of twin pregnancies deliver preterm, and it is unclear whether any intervention reduces this risk.

In twin gestations, although no overarching intervention was beneficial for the prevention of preterm birth and its sequelae, vaginal progesterone improved some important secondary outcome. ${ }^{4}$ Neither cerclage nor pessary has been proven an effective intervention for preventing 
preterm births and reducing perinatal deaths or neonatal morbidity in twin gestations. ${ }^{5}$

Nevertheless, the quest is underway for a rational preventive approach of preterm birth in twin gestations. The aim of our study was to compare the efficacy of a dual access of both vaginal progesterone and cervical cerclage with either solo management.

\section{METHODS}

Recruitment of participants who have met the eligibility criteria at the outpatient clinic of Menoufuia University Hospital extended between January 2015 and September 2016. All candidates have signed an informed consent. The trial has received acceptance of committee of medical ethics of Menoufia University Hospitals.

The participants who were eligible have fulfilled the inclusion criteria of a twin gestation at 12-16 weeks with a previous history of at least one spontaneous preterm labour or an incidentally mid trimester sonographic shortened cervical length $<2.5 \mathrm{~mm}$. They were subjected to a comprehensive history taking as well as thorough clinical examination, $\mathrm{CBC}$, fasting blood glucose, urine analysis and culture. We have utilized transvaginal ultrasonographic measurement of cervical length according to the technique described by Berghella and Bega. After the drop outs and those who discontinued the study have been excluded, those who continued were randomized via closed envelopes into the following 3 groups.

- Group $1(\mathrm{~N}-25)$ remedied with vaginal progesterone supplementation Two tablets of Progest (Pharco, Egypt), 100mg each inserted at night from 20weeks until 34 weeks of gestation.

- Group 2 (N-25) underwent Mc Donald type of cervical cerclage at 14-16 weeks.

- Group $3(\mathrm{~N}-25)$ were subjected to the dual approach of cervical cerclage of Mc Donald type at 14-16 weeks and vaginal progesterone tablets of $200 \mathrm{mg}$ nightly from 20 weeks until 34 weeks.

All participants were reviewed consecutively at 2 weeks intervals and followed up by sonographic measurement of cervical length until delivery. Outcome measures included occurrence of spontaneous preterm labour between 34 and 37 weeks and parameters of neonatal morbidity and mortality.

\section{Statistical analysis}

Results were tabulated and statistically analyzed by SPSS, with utilization of descriptive statistics as percentage, mean $(\mathrm{X})$ and standard deviation (SD) as well as analytic statistic parameters like Chi-square, t-test, and Mann Whitney U test.

\section{RESULTS}

After the exclusion of those patients who have not completed the study, either because of medically indicated pretem labour before end point of 34 weeks or patient non-compliance, actually a total of 75 participants underwent the final analysis of their data. They were randomized into three groups, each comprised twentyfive patients.

The demographic and obstetric characteristics of the three groups were contrasted in Table 1. There was no statistically significant difference among the three groups. The mean values of sonographically estimated cervical length measurements were 23.24 \pm 2.55 , $22.40 \pm 2.14$ and $22.76 \pm 2.24$ in progesterone group, cerclage group and combination group respectively.

The inter group difference did not show a statistical significance as depicted in Table 2.

Inter group comparison of gestational age at time of delivery was illustrated in Table 3.

There was significantly higher gestational age in combination group when compared to either progesterone or cerclage group $(\mathrm{P}<0.001)$. Conversely, there was a statistically non-significant difference in between progesterone and cerclage groups $(\mathrm{P}=0.85)$. Moreover, the gestational age at delivery among the three groups has been stratified into 3 strata: <34weeks, 34-37 weeks and $>37$ weeks as shown in Table 4.

There was significantly higher percentage of gestational age $<34$ weeks $(60 \%$ and $68 \%)$ in progesterone group and cerclage group respectively.

Table 5 demonstrated the inter group comparison of estimated birth weights. The progesterone and cerclage groups have shown significantly lower birth weight than in combination group $(\mathrm{P}<0.001)$ while there was nonsignificant difference between the first two groups.

A statistically significant lower Apgar score was shown in progesterone and cerclage groups than combination group $(\mathrm{P}<0.001)$ and such significant difference was lacking between the first two groups as shown in Table 6 .

NICU admission for different indications (breathing difficulty, neonatal sepsis, necrotizing enterocolitis, intracranial haemorrhage) was compared among the studied groups in Table 7.

As shown in the table, there was a significantly higher rate of NICU admission among progesterone and cerclage groups $(52 \%$ and $50 \%)$ respectively than in combination group $(6 \%)$ with $\mathrm{P}$ value $<0.001$. 
Table 1: Demographic and obstetric data of the study groups.

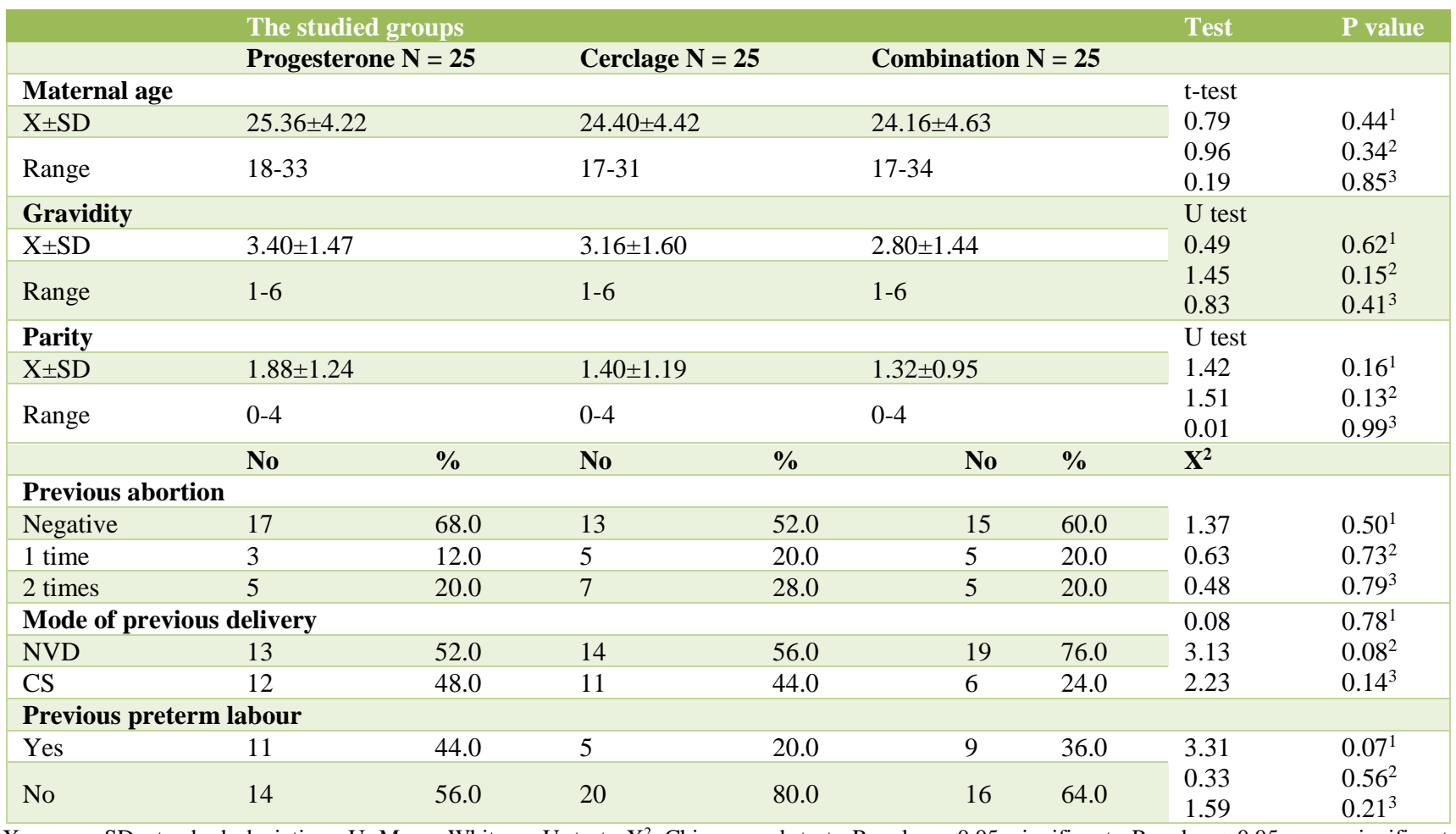

$\mathrm{X}=$ mean, $\mathrm{SD}=$ standard deviation, $\mathrm{U}=$ Mann Whitney $\mathrm{U}$ test, $\mathrm{X}^{2}=$ Chi squared test, $\mathrm{P}$ value $<0.05=$ significant, $\mathrm{P}$ value $>0.05=$ non- significant, $1=$ comparing progesterone group and cerclage group, $2=$ comparing progesterone group combined group, $3=$ Comparing cerclage group and combined gp

Table 2: Comparison of trans-vaginal cervical length among studied groups.

\begin{tabular}{|c|c|c|c|c|c|}
\hline & The studied groups & & & Test & $P$ value \\
\hline Cervical length/mm & Progesterone $N=25$ & Cerclage $N=25$ & Combination $N=25$ & t-test & \\
\hline $\mathrm{X} \pm \mathrm{SD}$ & $23.24 \pm 2.55$ & $22.40 \pm 2.14$ & $22.76 \pm 2.24$ & 1.26 & $0.21^{1}$ \\
\hline Range & $19-28$ & $19-27$ & $18-26$ & $\begin{array}{l}0.71 \\
0.58\end{array}$ & $\begin{array}{l}0.48^{2} \\
0.56^{3}\end{array}$ \\
\hline
\end{tabular}

$\mathrm{X}=$ mean, $\mathrm{SD}=$ standard deviation, $\mathrm{P}$ value $<0.05$ =significant, $\mathrm{P}$ value $>0.05=$ non-significant, $1=$ comparing progesterone group and cerclage group, $2=$ comparing progesterone group combined group, $3=$ comparing cerclage group and combined group

Table 3: Comparison of gestational age at delivery (mean \pm SD) among the studied groups.

\begin{tabular}{|lllll|l|}
\hline Gestational age at delivery weeks & Progesterone $\mathbf{N = 2 5}$ & Cerclage $\mathbf{N = 2 5}$ & Combination $\mathbf{N = 2 5}$ & \multicolumn{1}{c|}{ t-test } & \multicolumn{1}{c|}{ P value } \\
\hline $\mathrm{X} \pm \mathrm{SD}$ & $34.28 \pm 0.74$ & $34.24 \pm 0.72$ & $36.92 \pm 0.81$ & 0.19 & $0.85^{1}$ \\
\hline Range & $33-36$ & $33-36$ & $36-39$ & 12.03 & $<0.001^{2}$ \\
\hline
\end{tabular}

$\mathrm{X}=$ mean, $\mathrm{SD}=$ standard deviation, $\mathrm{P}$ value $<0.05=$ significant, $\mathrm{P}$ value $>0.05=$ non-significant, $1=$ comparing progesterone group and cerclage group, $2=$ comparing progesterone group combined group, $3=$ comparing cerclage group and combined group.

Table 4: Comparison of gestational age at delivery among the studied groups.

\begin{tabular}{|c|c|c|c|c|c|c|c|c|c|}
\hline & \multicolumn{7}{|c|}{ The studied groups } & \multirow[t]{2}{*}{ Test } & \multirow[t]{2}{*}{$P$ value } \\
\hline & \multicolumn{2}{|c|}{ Progesterone $N=25$} & \multicolumn{2}{|c|}{ Cerclage $N=25$} & \multicolumn{2}{|c|}{ Combination $N=25$} & & & \\
\hline & No & $\%$ & No & $\%$ & No & $\%$ & & $\mathbf{X}^{2}$ & \\
\hline \multicolumn{10}{|c|}{ Gestational age/weeks } \\
\hline$<34$ weeks & 15 & 60.0 & 17 & 68.0 & 2 & 8.0 & \multirow{3}{*}{$\begin{array}{l}26.4 \\
(<0.001)\end{array}$} & 0.35 & $0.56^{1}$ \\
\hline 34-37 weeks & 10 & 40.0 & 8 & 32.0 & 18 & 72.0 & & 17.23 & $<0.001^{2}$ \\
\hline > 37 weeks & 0 & 0.0 & 0 & 0.0 & 5 & 20.0 & & 20.69 & $<0.001^{3}$ \\
\hline \multicolumn{10}{|c|}{ Number of fetus } \\
\hline Single & 0 & 0 & 0 & 0 & 0 & 0 & ----- & ----- & ------ \\
\hline Double & 25 & 100 & 25 & 100 & 25 & 100 & & & \\
\hline
\end{tabular}

$\mathrm{X}=$ mean, $\mathrm{SD}=$ standard deviation, $\mathrm{X} 2=$ Chi squared test, $\mathrm{P}$ value $<0.05=$ significant, $\mathrm{P}$ value $>0.05=$ non-significant, $1=$ comparing progesterone group and cerclage group, $2=$ comparing progesterone group combined group, $3=$ comparing cerclage group and combined group. 
Table 5: Comparison of birth weight (Grams) among the studied groups.

\begin{tabular}{|c|c|c|c|c|c|c|}
\hline & The studied groups & & & & Test & $P$ value \\
\hline Birth weight & Progesterone $\mathbf{N}=\mathbf{5 0}$ & Cerclage $\mathbf{N}=\mathbf{5 0}$ & Combination $\mathrm{N}=\mathbf{5 0}$ & ANOVA & t-test & \\
\hline $\mathrm{X} \pm \mathrm{SD}$ & $2185.0 \pm 421.8$ & $2203.0 \pm 444.4$ & $2813.8 \pm 368.4$ & \multirow{2}{*}{$\begin{array}{l}37.6 \\
(<0.001)\end{array}$} & 0.21 & \multirow{2}{*}{$\begin{array}{l}0.84^{1} \\
<0.001^{2} \\
<0.001\end{array}$} \\
\hline Range & $1700-3250$ & $1700-3250$ & $1900-3300$ & & $\begin{array}{l}7.90 \\
7.50\end{array}$ & \\
\hline
\end{tabular}

$\mathrm{X}=$ mean, $\mathrm{SD}=$ standard deviation, $\mathrm{X}^{2}=$ Chi squared test, $\mathrm{P}$ value $<0.05=$ significant, $\mathrm{P}$ value $>0.05=$ non-significant, $\mathrm{P}$ value $<0.001=$ highly significant, $1=$ comparing progesterone group and cerclage group, $2=$ comparing progesterone group combined group, $3=$ comparing cerclage group and combined group

Table 6: Comparison of Apgar score among the studied groups.

\begin{tabular}{|lllll|l|}
\hline Apgar score & The studied groups & progesterone $\mathbf{N}=\mathbf{5 0}$ & Cerclage $\mathbf{N}=\mathbf{5 0}$ & Combination $\mathbf{N}=\mathbf{5 0}$ & $\mathbf{X}^{\mathbf{2}}(\mathbf{P}$ Value $)$ \\
\hline 0 & $10(20.0)$ & $13(26.0)$ & $0(0.0)$ & 47.2 & $1.06(0.59)$ \\
\hline 1 & $26(52.0)$ & $21(42.0)$ & $6(12.0)$ & $(<0.001)$ & $38.0(<0.001)$ \\
\hline 2 & $14(28.0)$ & $16(32.0)$ & $44(88.0)$ & $34.4(<0.001)$ \\
\hline
\end{tabular}

$\mathrm{X}=$ mean, $\mathrm{SD}=$ standard deviation, $\mathrm{X}^{2}=$ Chi squared test, $\mathrm{P}$ value $<0.05=$ significant, $\mathrm{P}$ value $>0.05=$ non-significant, $\mathrm{P}$ value $<0.001=$ highly significant, $1=$ comparing progesterone group and cerclage group, $2=$ comparing progesterone group combined group, $3=$ comparing cerclage group and combined group

Table 7: NICU admission and indications among the studied groups.

\begin{tabular}{|c|c|c|c|c|c|c|c|c|}
\hline & \multicolumn{6}{|c|}{ The studied groups } & \multirow[t]{2}{*}{ Test } & \multirow[t]{2}{*}{ P value } \\
\hline & \multicolumn{2}{|c|}{ Progestrone $\mathbf{N}=50$} & \multicolumn{2}{|c|}{ Cerclage $\mathbf{N}=\mathbf{5 0}$} & \multicolumn{2}{|c|}{ Combination $\mathbf{N}=\mathbf{5 0}$} & & \\
\hline & No & $\%$ & No & $\%$ & No & $\%$ & $\mathbf{X}^{2}$ & \\
\hline \multicolumn{9}{|l|}{ NICU admission } \\
\hline Admitted & 26 & 52.0 & 25 & 50.0 & 3 & 6.0 & \multirow[t]{2}{*}{29.3} & \multirow[t]{2}{*}{$<0.001$} \\
\hline Not admitted & 24 & 48.0 & 25 & 50.0 & 47 & 94.0 & & \\
\hline \multicolumn{7}{|l|}{ Cause of NICU admission } & \multirow{5}{*}{2.9} & \multirow{5}{*}{0.82} \\
\hline Respiratory distress & 15 & 57.7 & 13 & 52.0 & 3 & 100 & & \\
\hline Neonatal sepsis & 4 & 15.4 & 5 & 20.0 & 0 & 0 & & \\
\hline Necrotizing enterocolitis & 3 & 11.5 & 4 & 16.0 & 0 & 0 & & \\
\hline Intracranial haemorrhage & 4 & 15.4 & 3 & 12.0 & 0 & 0 & & \\
\hline
\end{tabular}

\section{DISCUSSION}

With a prevalence of less than $2 \%$ of all pregnancies, twin pregnancies account for more than $25 \%$ of spontaneous early preterm births. The rate of twin pregnancy in the USA has risen substantially over the last three decades. ${ }^{6}$ Multiple gestations contribute disproportionally worldwide to the burden of prematurity, primarily as a result of the increased risk of spontaneous delivery in the extremely preterm period. Infants delivered prior to 32 weeks of gestation account for almost half of all long-term neurological morbidity attributable to preterm delivery, and twins are between four and five times more likely than singletons to deliver before 32 weeks of gestation. ${ }^{7}$

Sonographic assessment of cervical length (CL) has long been shown to have comparable efficacy in predicting preterm delivery in twin gestations as in singletons. ${ }^{8}$ However, the two mainstays of therapy to reduce the risk of preterm delivery in singletons with short cervix, cervical cerclage and progesterone therapy, have yielded equivocal results in twins. ${ }^{9}$
To date, there is no strong evidence that either intervention reduces the risk of preterm delivery in twin gestations complicated by short cervix. ${ }^{2,10}$ Present study evaluated the impact of the dual approach of vaginal progesterone and cervical cerclage comparatively with either modality alone on the prevention of pretem labour among those with twin gestations demonstrating sonographic short cervix during their antenatal sonographic screening screening.

In our study neither progesterone nor cerclage alone have been found effective in preventing preterm labour in twin gestations. In this respect, we were in agreement with the results of another prospective cohort that mid trimester cervical cerclage did not alter the likelihood of prematurity associated with short cervical length in twin gestations. ${ }^{11}$ On the contrary, cervical cerclage was once mentioned by some authors that it should not be recommended in twin gestation with short cervix as it may exaggerate the risk of preterm birth. ${ }^{12}$

Present findings have not confirmed those of A retrospective study which demonstrated that in twin gestation with a short cervix, treatment with cervical 
cerclage may reduce the rate of early preterm birth. ${ }^{13}$ However, The main limitation of the forementioned study study arises from its retrospective nature and that it was not a randomized trial. ${ }^{13}$ Additionally, present findings were in agreement of other trials that vaginal progesterone was not associated with a significant reduction in the rate of preterm labour in twin gestations. ${ }^{14,15}$ Furthermore, some authors, found that vaginal progesterone therapy was associated with an increased risk of preterm delivery in their cohort retrospective study of twin pregnancies in women with short cervix. ${ }^{16}$

Conversely, and at variance with present findings, other clinical trials concluded that vaginal progesterone, administration in asymptomatic twin pregnancies with a sonographic short cervix (20-25 mm) at 20-24 weeks of gestation was found effective and safe treatment for reducing the incidence of preterm labor. ${ }^{17,18}$

In view of arguable issues concerning the efficacy of the use of progesterone or cerclage alone in preventing preterm birth in twin gestations, present study by far, may be one of only few if any, in the accessible literature which evaluated a dual approach of both progesterone and cervical cerclage in prevention of preterm labour in twin gestation. In current study, combined progesterone as well as cerclage was found efficacious in reducing preterm labour prior to 34 weeks and 34-37 weeks of gestation with a statistically significant difference when compared to either progesterone or cerclage groups while there was no significant difference between the two latter groups. Furthermore, some parameters of composite perinatal morbidity and mortality have been found improving in combination group compared to either progesterone or cerclage groups. Higher birth weight, higher Apgar score and lower likelihood of NICU admission was demonstrated in our study among combination group with a statistically significant difference from either progesterone or cerclage groups.

Along with present study, some other trials found that neither progesterone nor cerclage alone has demonstrated any positive impact on such parameters of perinatal morbidity and mortality. ${ }^{5,19-23}$ However. in contrary to present findings, other studies considered cervical cerclage was efficacious in improving some indicators of perinatal morbidity. ${ }^{24,25}$ In view of such a multitude of contradictory findings among different studies in assigning the efficacy of either solo progesterone or cervical circlage in preventing preterm labour and improving perinatal outcome in twin gestations, the rationale of studying a combination of both treatment was a logic target for present study.

\section{CONCLUSION}

In conclusion, our prospective randomized study of the dual approach of progesterone and cervical cerclage was found effectively improving both gestational age and perinatal outcome in twin gestations compared to either approach alone. However, further controlled studies on a bigger size of recruited population are required to validate present findings.

\section{Funding: No funding sources}

Conflict of interest: None declared

Ethical approval: The study was approved by the Institutional Ethics Committee

\section{REFERENCES}

1. Liu L, Oza S, Hogan D, Perin J, Rudan I, Lawn JE et al. Global, regional, and national causes of child mortality in 2000-13, with projections to inform post-2015 priorities: an updated systematic analysis. Lancet. 2015;385:430-40.

2. Romero R, Nicolaides K, Conde-Agudelo A, Tabor A, O'Brien JM, Cetingoz $\mathrm{E}$ et al. Vaginal progesterone in women with an asymptomatic sonographic short cervix in the mid trimester decreases preterm delivery and neonatal morbidity: a systematic review and meta analysis of individual patient data. Am J Obstet Gynecol. 2012;206:124 e119.

3. Berghella V, Seibel-Seamon J. Contemporary use of cervical cerclage. Clini Obstet Gynecol. 2007;50(2):468-77.

4. Jarde A, Lutsiv O, Park CK, Barrett J, Beyene J, Saito S, Dodd JM et al. Preterm birth prevention in twin pregnancies with progesterone, pessary, or cerclage: a systematic review and meta-analysis. BJOG. BJOG. 2017;124(8):1163-73.

5. Rafael TJ, Berghella V, Alfirevic Z. Cervical stitch (cerclage) for preventing preterm birth in multiple pregnancy. Cochrane Database Syst Rev. 2014;10;(9):CD009166.

6. Martin JA, Hamilton BE, Osterman MJK. Three decades of twin births in the United States, 19802009. NCHS Data Brief, no 80.2012; Hyattsville, MD: National Center for Health Statistics.

7. Goldenberg RL, Iams JD, Miodovnik M, Van Dorsten JP, Thurnau GS et al. The preterm prediction study: risk factors in twin gestations. National Institute of Child Health and Human Development Maternal-Fetal Medicine Units Network. Am J Obstet Gynecol. 1996;175:1047-53.

8. Conde-Agudelo A, Romero R, Hassan SS, Yeo L. Transvaginal sonographic cervical length for the prediction of spontaneous preterm birth in twin pregnancies: a systematic review and meta analysis. Am J Obstet Gynecol. 2010;203:128 e1-12.

9. Berghella V, Odibo AO, To MS, Rust OA, Althuisius SM. Cerclage for short cervix on ultrasonography: meta-analysis of trials using individual patient-level data. Obstet Gynecol. 2005;106:181-9.

10. Brubaker SG, Gyamfi C. Prediction and prevention of spontaneous preterm birth in twin gestations. Semin Perinatol. 2012;36:190-4. 
11. Newman RB, Krombach RS, Myers MC, MCGee DL. Effect of cerclage on obstetrical outcome in twin gestations with a shortened cervical length. Am J Obstet Gyncol. 2002;186:634-40.

12. Berghella V, Seibel-Seamon J. Contemporary use of cervical cerclage. Clin Obstet Gynecol. 2007;50(2):468-77.

13. Houlihan C, Poon LCY, Ciarlo M, Kim E, Guzman ER. Cervical cerclage for preterm birth prevention in twin gestation with short cervix: a retrospective cohort study. Ultrasound Obstet Gynecol. 2016;48(6):752-6.

14. Norman JE, Mackenzie F, Owen P, Mactier H, Hanretty K, Cooper S et al. Progesterone for the prevention of preterm birth in twin pregnancy (STOPPIT): a randomised, double-blind, placebocontrolled study and meta-analysis. Lancet. 2009;373(9680):2034-40.

15. Zacharakis D, Daskalakis G, Papantoniou N. Is treatment with cervical pessaries an option in pregnant women with a mid trimester short cervix? J Maternal Fetal Neonatal Med. 2012;25:52.

16. Brubaker SG, Pessel C, Zork N, Gyamfi-Bannerman $\mathrm{C}$, Ananth CV. Vaginal progesterone in women with twin gestations complicated by short cervix: a retrospective cohort study. BJOG. 2015;122(5):7128

17. El-refaie W, Abdelhafez MS, Badawy A. Vaginal progesterone for prevention of preterm labor in asymptomatic twin pregnancies with sonographic short cervix: a randomized clinical trial of efficacy and safety. Arch Gynecol Obstet. 2016;293(1):61-7.

18. Romero R, Conde-Agudelo A, El-Refaie W, Rode L. Vaginal progesterone decreases preterm birth and neonatal morbidity and mortality in women with a twin gestation and a short cervix: an updated metaanalysis of individual patient data. Ultrasound Obstet Gynecol. 2017;49(3):303-14.

19. Rode L, Klein K, Nicolaides KH, Krampl-Bettelheim E, Tabor A. Prevention of preterm delivery in twin gestations (PREDICT): a multicenter, randomized, placebo-controlled trial on the effect of vaginal micronized progesterone. Ultrasound Obstet Gynecol. 2011;38:272-80.

20. Combs CA, Garite T, Maurel K, Das A, Porto M. Obstetrix Collaborative Research Network. 17hydroxyprogesterone caproate for twin pregnancy: a double-blind, randomized clinical trial. Am J Obstet Gynecol. 2011;204(3):221.e1-8.

21. Schuit E, Stock S, Rode L, Rouse DJ, Lim AC, Norman JE et al. Effectiveness of progestogens to improve perinatal outcome in twin pregnancies: an individual participant data meta-analysis. BJOG. 2015;122(1):27-37.

22. Roman A, Rochelson B, Fox NS, Hoffman M, Berghella V, Patel V et al. Efficacy of ultrasoundindicated cerclage in twin pregnancies. Am J Obstet Gynecol. 2015;212(6):788.e1-6.

23. Vilchez G, Dai J, Maulik E, Sokol L. A retrospective cohort analysis of cerclage in Twin pregnancies: perinatal outcomes and gestational age at delivery. Am J Obstet Gynecol. 2017;216(1):S538-9.

24. Chavan MS, Jassawalla MJ. Comparison of perinatal outcome in twin pregnancy with and without cervical cerclage. Int J Reprod Contracept Obstet Gynecol. 2016;5(11):3924-30.

25. Bernabeu A, Goya M, Martra M, Suy A, Pratcorona L. Physical examination-indicated cerclage in singleton and twin pregnancies: maternal-fetal outcomes. J Maternal Fetal Neonatal Med. 2016;29(13):2109-13.

Cite this article as: Abdelaal N, Sanad Z, Shaheen A, Hamza H, Al Halaby A. Effect of vaginal progesterone in combination with cervical cerclage on improved gestational age and perinatal outcome in twin pregnancy: A prospective randomized study. Int J Reprod Contracept Obstet Gynecol 2017;6:3224-9. 